\title{
A Descriptive Study of Semantic-Pragmatic Language Disorder in Two Adults
}

\author{
Ibiere Ken-Maduako, Ph.D \\ Department of English, Ignatius Ajuru University of Education, Port Harcourt, Nigeria
}

\begin{abstract}
This paper studies the concept of semantic and pragmatic disorders in adults, using two adults as case study. We shall work within the theoretical framework of semantics, pragmatics and theories on semantic and pragmatic disorders. Our main finding is that this impairment does exist in adults who may exhibit very little obvious disability in their expressive language behaviour but manifest poor conversational and dialogical skills. They have a high tendency of misinterpreting utterances and are very easily misunderstood themselves.
\end{abstract}

Keywords: Dialogical, disorder, pragmatic, semantic.

DOI: $10.7176 / \mathrm{JLLL} / 60-03$

Publication date:September $30^{\text {th }} 2019$

\section{Introduction}

If one has ever been involved in a conversation with someone and begins to feel that he/she is really not making much progress or even that the person does not understand what is going on because the adult is responding like a child. No need to wonder. That person may be dealing with an adult who has a semantic-pragmatic disorder.

Semantic-pragmatic disorder (henceforth SPD) is a language or communication disorder commonly found in children and sometimes in adults. It is first noticed in children (between 18 months and 2 years), when they display noticeable delayed language development. Parents and other adults within the child's immediate community begin to feel that there's a little problem with the child even though they may not understand what it is initially. As the child begins to show evidences of acquisition of certain language skills, he/she may still have difficulty in understanding language used around him, he/she may also have difficulty using the language himself and operating efficiently or successfully in a conversation. Children with this impairment will typically sound odd and stilted in conversation, using memorized phrases inappropriately, out of context, echoing language, not sticking to the topic of conversation and not knowing what is being talked about. (See Babs web page, hi $2 \mathrm{u} 4$ people with hidden impairments). The children take language literally and do not understand figurative/idiomatic uses of language. This may become a real source of worry for concerned parents.

SPD is a developmental disorder which children seem to outgrow (at least the very bad signs) with age, care and sufficient support. As adults, they have become intelligible and are able to make good conversation. According to Babs, an SPD adult will just be a little eccentric. That is all that may be noticeable about them as adults. They look normal, talk normally and have jobs like every normal adult.

The above statements observations form the main preoccupation of this paper; do children outgrow SPD? Are there adults with this impairment? Most studies on SPD concentrate on children because it is during the childhood age that the disorder is most apparent. The present researcher was able to identify two adults with strange and unusual language behaviour that struck her that something was definitely wrong. The aim of the paper is therefore to explore and investigate the extent to which their linguistic behaviour show evidences of Semantic and Pragmatic Disorder.

\section{Methodology}

Data for this research generates from two adults; a male and female whose communicative behaviour had often baffled the researcher. The speech situations presented in this research are more than two years old because this observation has been on through time. Data was collected through informal observation and spontaneous interactions where subjects were unaware that they were being observed. Our subjects are educated second language (L2) speakers of English living in Port Harcourt, Rivers State, Nigeria.

\section{Definition of Terms}

\subsection{Semantics}

Semantics is the study of meaning communicated through language (Saeed 2003:3).

The aim of Semantics is to explain and describe meaning in natural languages. It is common knowledge that sentences from natural languages do not wear their semantic and logical form on their phonetic and orthographical sleeve. It is therefore apparent that we need a good knowledge of semantics to penetrate beyond surface meanings to derive hidden and underlying meanings of utterances. It is therefore the duty of semantics to describe all those features of meaning which remain invariable in whatever context they are used (Leech, 1969:5; Kratzer, 1977:337). 


\subsection{Pragmatics}

Mey (2001:6) propounded a very useful definition of pragmatics as a study of the use of language in human communication as determined by the conditions of society. In this paper, we have tried to define semantics as the study of meaning, expressed through language, by implication, literal meaning. In communication there is a need to sometimes determine whether an utterance is meant as a statement, guess, request or promise. It is this aspect of communication which focuses on the interactional part of communication that scholars term "the pragmatic aspect (Bartsch 1979:12). In other words, pragmatics may be also defined as the theory that deals with the conditions for the correct use of expressions and constructions in a given language. It deals with connotative rather than literal or conceptual meaning.

Grice argues that it is impossible to account for some aspects of conversational behaviour, unless we assume that people are cooperative. In his Cooperative principle, he proposes the following maxims necessary for communication:

1) Maxim of Quantity: Give the right amount of information

a) Make your contribution as informative as required for the current purposes of the exchange.

b) Do not make it more informative than required.

2) Maxim of Quality: Make your contribution one that is true;

a) Do not say what you believe to be false

b) Do not say that for which you lack adequate evidence

3) Relation: Be relevant

4) Manner: Avoid obscurity, ambiguity, be brief, be orderly.

\subsection{Semantic-Pragmatic Langauge Disorders}

A Semantic-Pragmatic language disorder is a term introduced into language studies by Rapin and Allen in 1983. It is used to refer to the impairment found in children and adults who show very mild autistic features but manifestation of semantic pragmatic language and communication deficiencies.

There are two types of Semantic pragmatic disorders:

1. Receptive Semantic-pragmatic disorder and

2. Expressive Semantic-pragmatic disorder

Receptive Semantic-pragmatic disorder is a situation where word comprehension is difficult for subject while expressive Semantic pragmatic disorder describes a situation where subject speaks out of context. Both are commonly characterized by poor conversational skills and inappropriacy in use of language.

\section{Historical Background}

As earlier stated, Rapin and Allen (1983) were the first to suggest the term and use it to describe the children with different communicative problems. They were observed in different behavioural traits such as:

- $\quad$ Pathological talkativeness.

- Insufficient access to vocabulary and discourse comprehension.

- Characteristic choice of terms (stereotyped).

- Inappropriate conversational skills.

\section{Semantic Disorders}

Semantics is that area of language study that is concerned with understanding the meaning of words, phrases and sentences and using those words appropriately in speech. People with semantic difficulties especially children are unable to understand the meaning of lexical items, words, phrases and sentences.

There is evident difficulty with abstract or vague words, especially those that have to do with feelings and emotions. Again, they also experience difficulty with idioms, metaphorical and figurative expressions since they take them literally. The old man kicked the bucket "would mean just that to them. An example was given of a fourteen year old who was asked if he enjoyed spending time with his friends. He didn't understand how one can "spend time". All he knows is to spend "money" (Bowen 2001). Semantic disabilities also reflect in their inability to identify key points in a sentence or discussion.

Consequently, they may change the topic suddenly thinking they are still on the same topic. Another example of an eleven (11) year old girl is useful at this point, she was asked:

D: Could you get the book off the shelf and give it to me?

Reply: The Gulf Stream warms coast line.

Apparently, she made an obscure connection between "shelf" and "gulf" stream", which may have been as a result of her deep interest in marine biology and ocean currents (Bowen 2001).

\section{Pragmatic Disorders}

Pragmatics is the area of language study concerned with the use of language in social contexts. In other words, 
knowing what to say, how to say it, when to say it, and how "to be" with other people in conversation. H.P Grice in his cooperative principle believes that, human beings communicating are in a sort of co-operative activity. A speaker always takes his turn and gives his interlocutor an opportunity to take his own turn.

However, people with pragmatic difficulties have problem using language in socially acceptable ways. They do not recognize turn-taking in speech and so may "talk over the top of one's head". Sometimes, they respond to speeches that require answers with an inappropriate silence (not a deliberate silence).

Other features of pragmatic disorder are;

- $\quad$ Excessive interruptions

- Irrelevant talks

- Uninteresting conversation

Their communicative behaviour seems rude and inconsiderate.

In the next section, we shall be considering what is considered pragmatic skills in communication.

\subsection{Pragmatic Skills}

1) Knowledge that one has to give an answer when a question is asked.

2) Ability to participate in conversation by taking turns with other speakers.

3) Ability to notice and respond to non-verbal language behaviour, reaction in appropriate ways to the other person's body language and mood. People with Semantic-Pragmatic disorder tend to change their mind with a little pressure; an impulsive act.

4) Awareness that one has to introduce a topic in such a way that your listener understands fully.

5) Knowing word and sentence type to employ when initiating a conversation and to also respond appropriately to speech directed at you.

6) Ability to maintain a topic (if you must change, do so appropriately and politely).

7) Ability to maintain appropriate eye contact during a conversation (that is not staring and not looking away).

8) Ability to distinguish how to talk and behave towards different communicative partners, responding to both formal and informal speech situations.

\subsection{Causes and Characteristics}

The major cause of this impairment is yet uncertain. But research findings have shown that it must have some generic origin and the basic characteristics are as follows:

1. Delayed language development.

2. Aphasic speech (word search palsies, word orders errors, verb - tense and

3. Difficulty with pronouns or pronoun reversal.

4. Difficulty in understanding questions.

- $\quad$ Understanding choices or making decisions.

- Difficulty in following stories or conversations (and their own conversations are off topic or one-sided).

- Difficulty with extracting key points, they get lost in the details

- Difficulty with tense of verbs.

- Difficulty with explanations or description of events.

- $\quad$ Tendency to be concrete and to prefer facts to stories.

- Difficulty with understanding or taking satire or jokes.

- Difficulty with understanding contextual clues.

- Difficulty in reading comprehension.

- Difficulty in body language reading.

- Difficulty in making and maintaining friendship and relationships because of delayed language development.

- $\quad$ Difficulty with distinguishing offensive remarks.

- Difficulty with organizational skills.

They may display marvelous abilities in Maths, Computer, Geography, Astronomy, Reading, History, Sports, Politics and Music. According to Bishop and Norbury (2002), children with SPD may be fluent in language production and have clearly articulated expressive language but they exhibit problem in the area of pragmatics or language use.

\subsection{Early Signs between Ages 0-4}

1 Quiet baby. They are content most of the time

2 Like to play alone repetitively

3 Difficult toddler with no sense of danger 


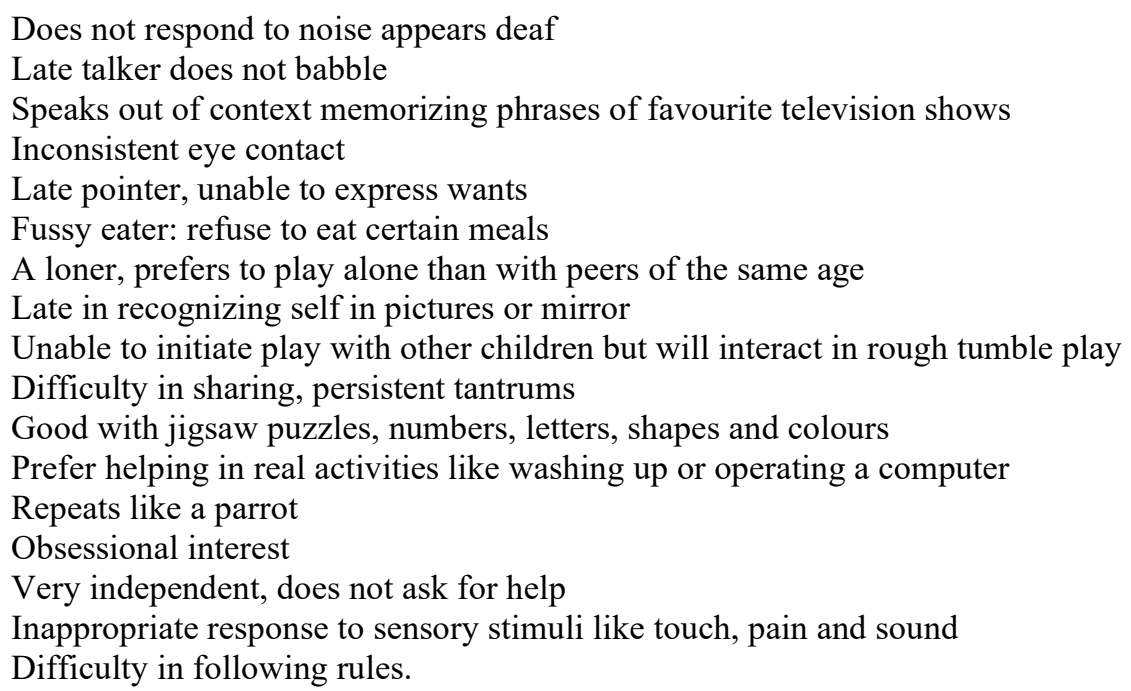

\subsection{Distinction between Autism, Semantic Pragmatic Disorder and Asperger's Syndrome}

In an article discussing the boundaries between autism, Asperger's syndrome and SPD, Bishop (1989) quoted Rapin's findings in support of the view that Autism and developmental language disorder were not mutually exclusive and that the best approach was that of a continuum. Bishop's proposed continuum model had two dimensions: firstly, that of meaningful verbal communication and secondly that of interests and social relationships. In avoiding a single continuum of severity, Bishop was able to contrast the pattern of symptoms between the disorders. Thus, children with relatively normal communication but abnormal social relationships would have Asperger's syndrome, children with relatively normal social relationships but abnormal verbal communication would have SPD and those with abnormal abilities for each criteria would be children with autism.

Furthermore, Brook and Bowler (1992) express the opinion that both autism and SPD resulted from the same fundamental cognitive and interpersonal difficulties and should be included in the autistic continuum. For them, "SPD" and "autism" are different perceptions of the same phenomenon. They concluded that more research was required to explain the social - cognitive abilities of children with SPD (Shields, 1996; Gagnon, 1997:45; Wing, 1996:73).

\section{Analysis and Discussion}

In this section, we shall be considering some conversations from our data in order to highlight traces of semantic-pragmatic disorders and other instances of conversational inappropriacy. Our analysis shall be under the following sub-categories.

1. Expressive Semantic disorder (speaking out of context)

2. Receptive Semantic disorder - Inability to understand literal word meaning.

3. Pragmatic disorders :

a. Violation of exchange structure.

(i) Nil response (Avoidance Strategy)

(ii) Not employing context in comprehension

(iii) Inappropriate presupposition

(iv) Too much information

(v) Unnecessary assertion/denial

(vi) Excessive elaboration

(vii) Unnecessary reiteration

4. Unusually or socially inappropriate content and style as exemplified in topic drift, unmarked topic shift and inappropriate questioning (Bishop and Adams 1989: 244).

\subsection{Expressive Semantic Disorder}

Bishop and Adams (1989: 245) recorded the following inappropriate speech as an example of expressive errors.

\section{CONVERSATION I}

A: Why did you have to go to the Doctor?

C: $\quad$ I used to have a headache.

(Error in tense)

In our study however, a related inappropriate response was observed when our female subject was hospitalized. 
S: Where have you been?

F: $\quad$ I was in the hospital.

S: Why were you admitted in the hospital?

F: I ran away for some days.

(The inappropriacy is found in "ran" anybody "admitted" in the hospital does not "run" away). The respondent may have decided to feign sickness because she was tired of the work load at home and decided to pretend to be sick in order to be admitted in the hospital.

Errors in tense, wrong verbs, prepositions, etc. may not be rampant in adult speech as we find with children. Except may be with the uneducated and low class and then it may not be an SPD.

\subsection{Receptive Semantic Disorder}

Inability to understand literal meaning - evidence from our research shows that our subjects did not exhibit much of this disorder. With children, they give an inappropriate response to a question asked by an adult. But with adults, it is not that simplistic: e.g. For children:

A: Where did you go on holiday?

C: $\quad$ In September.

A: What other kind of party could it be?

C: $\quad$ Cakes and drinks.

For the adults, it is a bit more complicated. For example we observed the following inappropriate response from the male respondent:

A: Isn't your cousin's house by the corner?

B: $\quad$ So that you can go and gossip? Because gossiping is so sweet?

The child may not have understood the meaning of the lexical items used and so brings an inappropriate response or the child just felt like keeping the conversation going and so gives an answer whether it was suitable or not. For the adult however, the male respondent believes that the question about the cousin's house meant that A wanted to go to visit the cousin and indulge in some gossip with the cousin.

\subsection{Pragmatic Disorder}

(a) Violation of exchange structure; this describes situations when subjects do not obey conversational rules or produce utterances appropriately for coherent communication. Some evidences are presented below:

(i) NIL RESPONSE: (Silence)

This happens in a conversation when one party does not respond, not even an "I don't know". Our subjects in this study tended to exhibit this trait to a large extent. Our female subject, (henceforth " $F$ "), usually does this when distracted. It takes her time to come back and if prodded responds with a:

F: $\quad H m . . . ?$ (as if distracted and lost in thought).

For the male subject, henceforth "M", he does this when he does not fully comprehend what has been said and needs time to think. For him, it is an avoidance strategy.

(ii) Failure to adopt context in comprehension.

This is when subject understands the literal meaning of an utterance but overlooks the context and illocutionary force of the utterance.

\section{CONVERSATION 3:}

S: $\quad$ F, can you tell me how the meeting went?

F: $\quad$ Yes I can

(But does not proceed to fulfill the promise) Or

S: $\quad$ F, please tell your husband that I'd like to see him?

F: $\quad$ Ok (but she does not move an inch).

\subsection{Inappropriate Presupposition}

Presupposition refers to what the speaker has in mind before making an utterance. In our study, $\mathbf{M}$ suspects $\mathbf{S}$ and another friend are having affair. He sees the friend as he was going out around $\mathbf{S}$ 's house and wrongly presupposes that the friend had visited $\mathbf{S}$ :

M: How was your day?

S: $\quad$ Fine, thank you.

M: He was well entertained, wasn't he?

S: $\quad$ Who was?

M: $\quad$ Stop pretending

S: Who? What are you talking about?

M: $\quad$ I saw him. You're pretending.

Conversation 3 seems to confirm our suspicion that adults with SPD tend to be unsure of themselves and are 
highly suspicious. As can be seen below, other utterances fit into this category.

\section{SCENE: In a classroom.}

$\mathbf{S}$ and $\mathbf{M}$ had just returned from an event they attended.

S: $\quad$ Please excuse me.

M: $\quad$ Silence

(S returns a few minutes later and enquires)

S: $\quad$ Are you ready for dinner?

M: Where did you go?

S: $\quad$ To pray.

M: Why did you not pray with me?

S: $\quad$ (Surprised and remain silent)

M: $\quad$ Is it because you think I'm not spiritual enough to pray with you?

S: $\quad$ Speechless at this insinuation and conclusion but said nothing more.

\section{CONVERSATION 6}

$\mathrm{S}$ visits $\mathrm{F}$ and a gift is presented, a beautiful earring. As the guest, $\mathrm{S}$, lay down to sleep, she pulled off the earrings and placed them on top of the refrigerator. She forgot it as she was leaving. The next day, the following conversation ensued:

S: $\quad$ Hey, I forgot my earrings in your house.

F: (Grunts) hm, hm, hm?

S: $\quad$ Did you see them?

F: (Obviously upset).

You were looking for a way to end the friendship and you did not know how to tell me to my face so you purposely left the earrings as a sign of rejection.

S: $\quad$ Ah! Ah!

F: $\quad$ I know people have been telling you things and you've been listening to them.

( $\mathbf{S}$ is shocked. $\mathbf{F}$ is not convinced and is no longer interested in the discussion).

\section{(iv) TOO MUCH INFORMATION}

According to Grice in his maxim of quantity, do not make your contribution more informative than required. Research has shown that people with SPD tend to flout this maxim. Children with SPD are known to be talkative and repetitive. For instance, F lost a pregnancy and on S's enquiry about it, she goes on to confirm and tell how the pregnancy had been a mistake, an accident and lets $\mathbf{S}$ into other secrets that cannot be put down on paper.

\section{UNNECESSARY ASSERTION / DENIALS}

From our study, we observed that this was a trait found in our subjects especially F, who would with a high pitched voice make assertions that were unnecessary, when she was denying something. She would almost do it with a shriek No!. its not me, I didn't do it. This was also done repeatedly.

\section{EXCESSIVE ELABORATION}

This was also a feature characteristic of our subjects. In making explanations, $\mathbf{M}$ seems to take a lot of time to give a detailed explanation with so many analogies and examples that one could get bored. Sometimes, before he would get to the real point he wanted to make, one would have lost track of what it was all about. Many times, $\mathbf{S}$ has found herself complaining; please get to the point now!!

(viii) A related feature is that of unnecessary reiteration, using other words to make the same point. This is also a feature characteristic of $\mathbf{M}$ who has an analytical mind.

As research has confirmed, children with SPD outgrow some of the autistic traits after some time, that is, they begin to talk more fluently and may stick to the topic of conversation to some extent. Nevertheless, in adult life, some traces still seep through as our study seeks to establish. Let us still consider the following conversations to highlight more characteristics:

5. HIGH SUSPICION:

Every movement around people with SPD which they cannot understand is met with great suspicion that something is going on behind them (something negative usually).

CONVERSATION 7:

Two friends go into the hotel to see a friend. S had to see a client alone and as she comes out:

S: Oh! What a day!

M: (Silence)

S: Today is very hot or haven't you noticed?

M: (Still Silence). (Then angrily he bursts out):

You are such a disgrace! So you sneaked in to see Mr. Tony?

I'm just wasting my time with you. You're not a worthy

Friend! 
S: (thoroughly confused). Went in to see who? What are you talking about?

$M$ Storms out of the place.

6. INAPPROPRIATE QUESTIONING:

CONVERSATION 8:

Discussion on another topic was going on and with a concerned voice:

S: Queeneth didn't do so well in school last term, I wonder why.

M: ( Queeneth's younger sister walks into the room)

$\mathrm{M}$ : But is this girl growing at all?

S: I'm saying something important and you are just...

(S walks away with a hiss).

7. USE OF MEMORIZED PHRASES:

Children with SPD may memorize phrases from television shows they love and it is that simple. With the adults, in addition to that, they may have to rehearse every intended speech they have to make (Maybe a meeting with a new client ) alone in the room, before a mirror, etc. They are usually too embarrassed to do it before someone else, even a spouse. This confirms to a great extent earlier research that stipulated that SPD children have stereotyped speech patterns, using only familiar terms and memorized phrases. So, as adults they have to familiarize themselves with new terms so they can use them without difficulty.

\subsection{Feelings of Insecurity and Mood Swings}

Every conversation and laughter that happens around them is about them. Feelings of insecurity follow them from their childhood maybe because of the mockery they had received from peers, teachers and family members due to their poor conversational skills.

CONVERSATION 9:

Child: Mummy, Auntie Idowu is looking for you.

F: Tell her I'm not in. ( and she rushes out to hide).

Child: But I have already told her you're in.

F: Ok, tell her I'm in. (She rushes back but Auntie Idowu was already within hearing distance and had heard all that had transpired).

In addition to these mood swings, they sometimes appear inconsiderate and selfish. They seem unaware of other's problems:

CONVERSATION 9b:

Three people are in a car. F and husband and $\mathrm{S}$ wanted to see a family friend. Hubbie had driven almost three quarters of the distance when F suddenly bursts out:

F: Let's go and see Sister.

H: But you said we should see KK.

F: No, let's see Sister.

$\mathrm{H}$ : This is the kind of thing that I don't like o!

F: Ok, Sorry. Let's see Kk ( No mischief intended, no offence taken).

8. ABRUPT CHANGE OF TOPIC ( AN AVOIDANCE STRATEGY?):

CONVERSATION 10:

$\mathrm{S}$ : It looks like the rains are about to come.

M: Eh?

$\mathrm{S}$ : The rainy season is on its way.

M: But is he a good man?

S: Who?

M: Gwan de Diablo. Is he a good man?

S: Gives him a long hiss and walks away.(S could not understand the deviation)

9. SUSPICION:

CONVERSATION 11:

After a church service, on their way home:

M: That preacher was talking about me.

S: No, he wasn't! He was speaking generally about people's behaviours.

M: Hypocrite! Betrayer! You told him about me.

S: (Surprised) Me? Told him what? Do I even know him?

M: You go behind me and gossip about me.

S: God have mercy! What is going on?

Unlike the child's exhibition of inappropriacy and out of context conversational style, the adult is more sophisticated, technical and suspicious! 


\section{MISINTERPRETATION:}

CONVERSATION 12:

At the end of a talk, as the two friends walk home:

S: I had a splendid time today. What about you?

M: That man did not fool me.

S: How?

M: When he mentioned 'irresponsible men', I knew he was talking about me.

$\mathrm{S}$ : Of course not! Does he even know you?

\section{Findings:}

1. This study has tried to show that SPD is not only a children's affair. Adults also exhibit these traits although at a reduced, more sophisticated and subdued level. Except you are close friends with an SPD adult you may never know but you would always wonder why his/ her reasoning is queer and different.

2. SPD adults are always misunderstood in interactive events and they also misunderstand people and their intentions.

3. Because they cannot understand the world around them, they are prone to throwing tantrums

4. They are always anxious about how people feel about them and their language behavior. Consequently, after some interaction, they may come to ask a close friend how they conducted themselves in the discussion.

5. Because of feelings of insecurity, they are firm and resolute in their decisions so no one messes with them.

6. As a result of their feelings of insecurity which also leads to anxiety, they are always stressed. Children reduce the stress through repetitive behavior such as crying, rocking, tantrumming and hitting. The adult on the other hand, becomes withdrawn, violent and a striker. The female adult may still retain the childhood traits of crying and tantrumming

\section{Conclusion}

Evidences from our study prove that SPD is an impairment that both children and adults suffer although with the adults it is a bit reduced. As speech therapists are attending to the children, let the adults be helped also because their communicative behavior can be irritating and embarrassing. As we have seen, it is something generic and innate and so we urge that people should show more sensitivity and empathy when dealing with such people. We believe that with some speech and behavioural therapy, these adults can be helped.

\section{References}

Bartsch (1979) Semantically and Pragmatically Correctness as Basic Notions of the Theory of Meaning in Journal of Pragmatics Vol. 3.

Bishop, D.V.M. (1989) Autism, Asperger's Syndrome and Semantic Pragmatic Disorders. Where are the Boundaries? British Journal of Disorders of Communication, 24, 69, Pp107-121.

Bishop, D.V.M. (2000) Pragmatic Language Impairment: A Correlated of SLI, A District Subgroup or Part of the Artistic Continuum? In D.V.M. Bishop and L.B. Leonard (eds) Speech and Language Impairments in Children: Causes, Characteristics, Intervention and Outcome. Hove Uk: Psychology Press. Pp 99-113

Bishop, D.V. Norbury (2002). Exploring the Borderlands of Autistic Disorder and Specific Language Improvement: A Study Using Standardized Diagnostic Instruments. Journal of Child Psychology and Psychiatry and Allied Disciplines 43, (7): 917-29.

Bishop, D.V.M. and C. Adams (1989). Conversational Characteristics of Children with Semantic and Pragmatic Disorders. What Features Lead to a Judgment of Inappropriacy? British Journal of Disorder of Communication, 24, 241-263.

Brook, S. L. and Bowler, D. (1992). Autism by another Name? Semantic and Pragmatic Impairment in Children. Journal of Autism and Developmental Disorder, 22. Pp61-81.

Gagnon, L. Mottron, L. and Joanette, Y. (1997). Questioning the Validity of the Semantic Pragmatic Syndrome Diagnosis. Autism, I (1) pp 37-55.

Greonendijk, J. and Stokhof, M. (1978). Semantic, Pragmatic and the Theory of Meaning in Journal of Pragmatics Vol. 2.

Kratzer, A. (1977). What Must and "Can" Must and Can Mean in Linguistics and Philosophy Vol. 1, No. 3.

Leech, (1969). Towards a Semantic Description of English - London: Longman.

Mey, L. J. (2001). Pragmatics, An Introduction. USA: Blackwell Publishing.

Ravin I. and Allan, D. (1983). Developmental Language Disorders: Nosolgic Considerations in U. Kirk (ed) Neuropsychology of Language, Reading and Spelling, pp.155-184. New York: Academic Press.

Saheed, J. I. (2003). Semantics USA: Blackwell Publishing. 
Shields J. et al. (1996a). Hemispheric Function in Developmental Language Disorders and High Level Autism: Developmental Medicine and Child Neurology, 38, pp.437-486.

Wing, L. (1996). The Autistic Spectrum: A Guide for Parents and Professional London: Constable.

Babs in A. Hayes (online) Hi2U. http://www.hizu.org/visitors/spd/ntm

Muggleton, J. (1977) What is Semantic - Pragmatic Disorder? National Autistic Society (Surrey Branch) http://www.mugsy.org/spd/htm 